\title{
Canonical and Noncanonical Wnt Signaling in Neural Stem/Progenitor Cells
}

Nora Bengoa-Vergniory ${ }^{1 *}$ and Robert M. Kypta ${ }^{1,2}$

${ }^{1}$ Cell Biology and Stem Cells Unit, CIC bioGUNE, Bilbao, Spain

2 Department of Surgery and Cancer, Imperial College London, London, UK

* Present address Department of Physiology, Anatomy and Genetics, Oxford University, UK

*Correspondence: nora.bengoa-vergniory@dpag.ox.ac.uk, rkypta@cicbiogune.es, r.kypta@imperial.ac.uk

Running title: Wnts in Neural Stem Cells 


\begin{abstract}
The first mammalian Wnt to be discovered, Wnt-1, was found to be essential for the development of a large part of the mouse brain over 25 years ago. We have since learned that Wnt family secreted glycolipoproteins, of which there are nineteen, activate a diverse network of signals that are particularly important during embryonic development and tissue regeneration. Wht signals in the developing and adult brain can drive neural stem cell self-renewal, expansion, asymmetric cell division, maturation and differentiation. The molecular events that take place after a Wnt binds to its cell-surface receptors are complex and, at times, controversial. A deeper understanding of these events is anticipated to lead to improvements in the treatment of neurodegenerative diseases and stem cell-based replacement therapies. Here we review the roles played by Wnts in neural stem cells in the developing mouse brain, at neurogenic sites of the adult mouse and in neural stem cell culture models.
\end{abstract}

Keywords: Wnt signaling, neural stem cells, beta-catenin, AP-1 family transcription factors 


\section{Wnt signaling}

Wnt proteins play roles in many cellular and physiological processes, regulating cell proliferation, differentiation, migration and patterning during embryonic development and tissue homeostasis in the adult $[1,2]$. The Wnt family in mammals is comprised of nineteen secreted glycolipoproteins that are able to bind to a wide variety of receptors and elicit a number of different responses in the cell [3]. These have classically been divided into canonical ( $\beta$-catenin-dependent) and noncanonical ( $\beta$-catenin-independent) Wnt signaling pathways.

\section{Canonical Wnt signaling}

In the canonical Wnt signaling pathway, $\beta$-catenin is actively degraded by a protein complex that includes Axin, glycogen synthase kinase-3 (GSK-3), casein kinase 1 (CK1) and adenomatous polyposis coli (APC). In the classical pathway, binding of a Wnt protein to receptors of the frizzled (FZD) and low-density lipoprotein receptor-related protein (LRP5/6) families leads to membrane recruitment of Axin and disheveled (DVL), thereby disrupting the function of the degradation complex. $\beta$-catenin is thus stabilized, enters the nucleus and activates genes in association with T-cell factor/lymphoid enhancer factor-1 (TCF/LEF) family transcription factors [1]. However, a more recent version of the model (Fig. 1) posits that the destruction complex is not disrupted by Wnt activation and that changes in the levels of free and transcriptionally active $\beta$-catenin result from relocation of the complex to the membrane, which disrupts $\beta$-catenin ubiquitination rather that the complex itself, leading to $\beta$-catenin accumulation [4]. Other extracellular ligands have been shown to alter the output of the pathway. Members of the Dickkopf and 
sFRP families, and WIF1 and Cerberus can bind to Wnt receptors or Wnt ligands inhibiting or, in some instances, enhancing their effects $[5,6]$. In addition, Rspondins (RSPOs) modulate the Wnt response at the cell membrane by binding to leucine-rich repeat containing G protein-coupled receptors (LGRs) [3].

The canonical pathway is implicated in many human diseases [2]. Perturbations in the levels of Axin, APC, $\beta$-catenin, LEF1 or TCF4, for example, contribute to the initiation and/or progression of several different types of cancer [7-12]. It is therefore not surprising that so much effort has gone into the development of new drugs based on our knowledge of Wnt signaling to treat disease. Among the commercially available drugs that have been developed to manipulate Wnt signaling are IWP-2 and Wnt-C59, potent porcupine inhibitors that block Wnt secretion [13, 14], IWR-1 and XAV939, which are tankyrase inhibitors that stabilize Axin and thereby inhibiting canonical Wnt signaling [13, 15], CHIR99021 (CHIR), a GSK-3 inhibitor that activates Wnt signaling [16], and iCRT-14, which inhibits the $\beta$-catenin/TCF complex [17]. These inhibitors, as well as several others not mentioned here, have been important for driving progress of research in this field, and the development of possible therapies for Wnt-related diseases. 


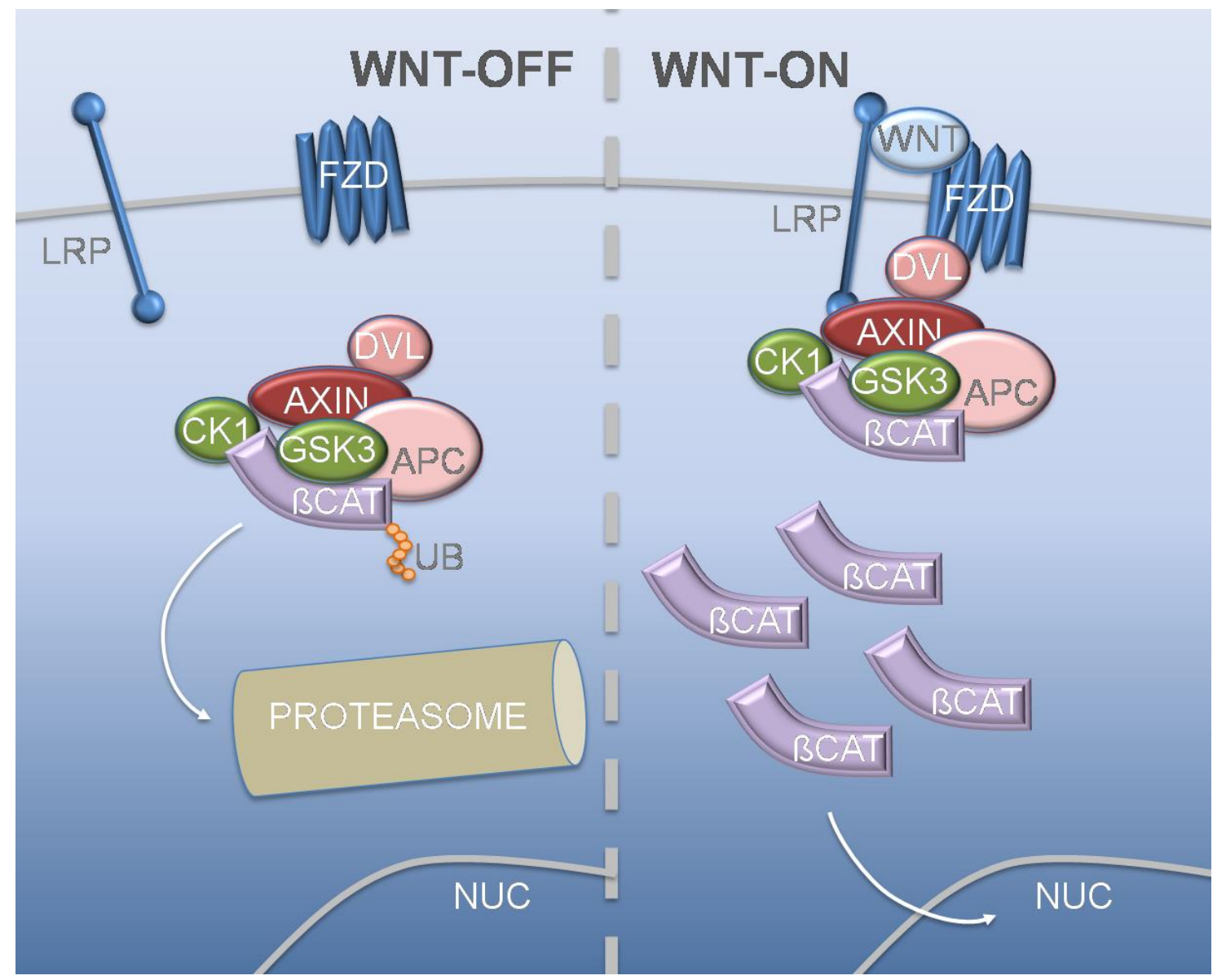

Figure 1. Representation of canonical Wnt signaling, according to Li et al. [4].

Wht binds to FZD receptors and LRP5/6 co-receptors, recruiting the destruction complex to the membrane, thereby preventing $\beta$-catenin $(\beta$-CAT) ubiquitination, leading to its accumulation and entry into the nucleus; ubiquitin, UB; nucleus, NUC.

\section{Noncanonical Wnt signaling}

Noncanonical Wnt signals (Fig. 2) regulate DVL and other intracellular proteins to activate the Planar Cell Polarity (PCP) pathway, the Wnt-Calcium $\left(\mathrm{Ca}^{2+}\right)$ pathway and other $\beta$-catenin/TCF-independent events [18]. In the Wnt-PCP pathway, FZD receptors activate a signaling cascade that involves the small GTPases Rho and Rac and c-Jun $\mathrm{N}$-terminal kinase (JNK), leading to changes in the cytoskeleton and activation of Activator Protein-1 (AP-1) family transcription factors [19]. Noncanonical Wnt stimuli induce association of DVL associated activator of 
morphogenesis (DAAM) proteins with FZD, DVL and GTP-bound Rho, which is then able to activate Rho-associated, coiled-coil containing protein kinase (ROCK) and even JNK. Although JNK is generally associated with phosphorylation and activation of c-Jun, it phosphorylates many other proteins, including activating transcription factor 2 (ATF2) and cyclic AMP response element-binding protein (CREB), which heterodimerize with c-Jun and other AP-1 family members to alter gene expression [20]. This pathway regulates cell polarity in several morphogenetic processes in vertebrates, including gastrulation, neural tube closure and orientation of stereocilia in the inner ear [19].

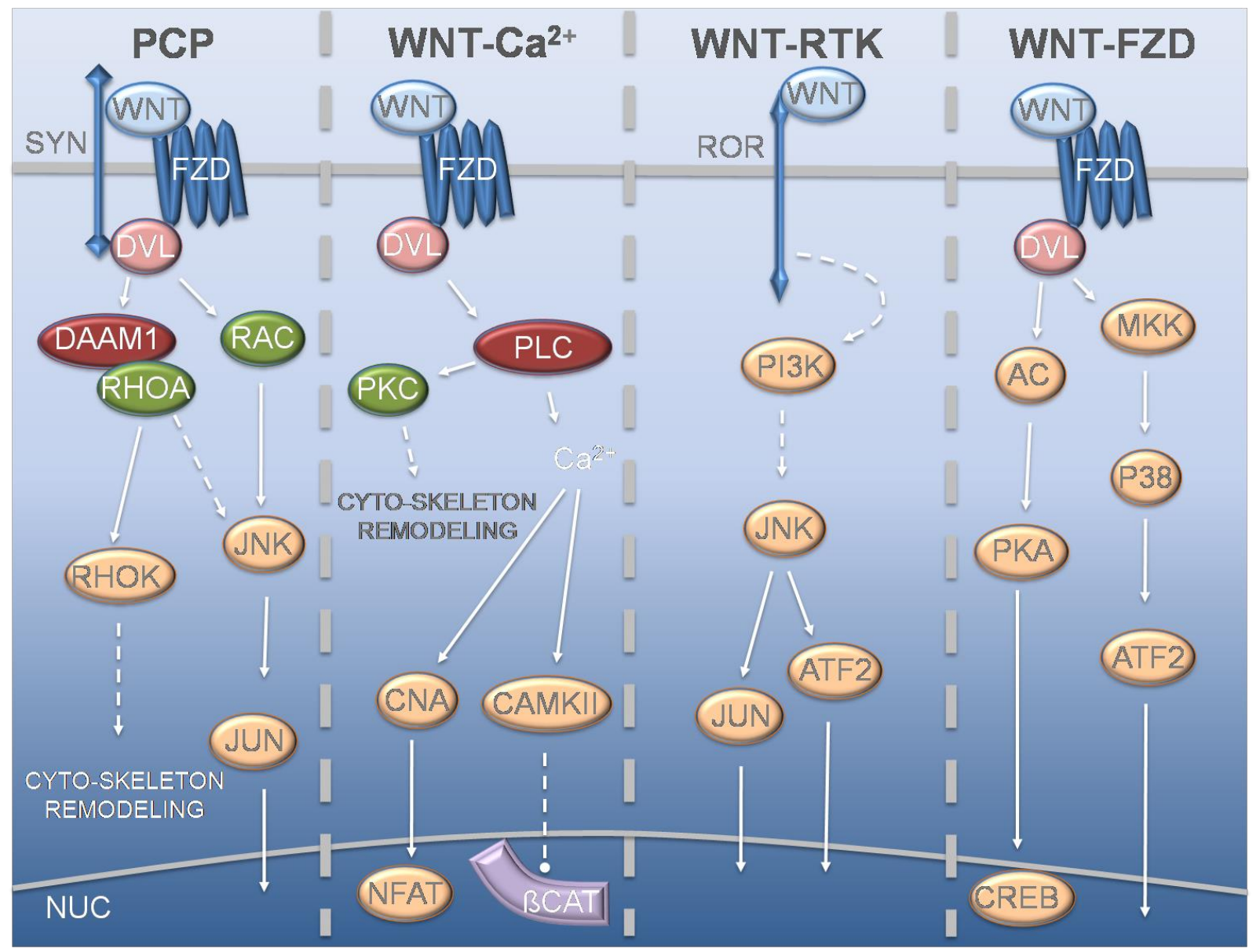

Figure 2. Schematic representation of noncanonical Wnt signaling

Noncanonical Wnt signals activate several different pathways through distinct intracellular effectors. In the PCP pathway, Wnt activates Rho kinase (ROCK) and 
JNK, thereby eliciting changes in gene expression and remodeling of the cytoskeleton. In the Wnt-Calcium pathway, DVL activation triggers activation of protein kinase $\mathrm{C}(\mathrm{PKC})$ and $\mathrm{Ca}^{2+}$ release. This then activates nuclear factor of activated T-cells (NFAT)-dependent gene expression, with concomitant inhibition of $\beta$-CAT. Receptor tyrosine kinases (RTKs) activate phosphoinositide-3 kinase (PI3K), which can result in JNK activation. FZD receptors can activate several intracellular effectors, including protein kinase A (PKA) and p38 kinases. Syndecan, SYN; dishevelled associated activator of morphogenesis 1, DAAM1; Calcineurin, CNA; calmodulin kinase II, CAMKII; phospholipase C, PLC; adenylate cyclase, AC; mitogen-activated protein kinase kinase, MKK.

In the Wnt-Ca ${ }^{2+}$ pathway, Wnt binding to FZD receptors activates DVL, leading to activation of phospholipase C (PLC), producing 1,2 diacylglycerol (DAG), which activates protein kinase C (PKC), and inositol 1,4,5-tri-phosphate (IP3), which activates calcium release from the endoplasmic reticulum. Other events such as activation of ROCK have also been linked to this pathway [21]. Calcium release activates calcineurin (CNA) and $\mathrm{Ca}^{2+} /$ calmodulin-dependent protein kinase II (CAMKII), which respectively increase expression of nuclear factor of activated Tcells (NFAT)-dependent genes and inhibit canonical Wnt signaling through nemolike kinase (NLK) [22]. This pathway is involved in cancer, inflammation and neurodegeneration $[3,23]$.

Even at the cell surface, noncanonical Wnt signaling is highly variable and complex, with Wnt ligands interacting not only with FZD but also with numerous other receptors, including receptor tyrosine kinase-like orphan receptor (ROR1/2), receptor-like tyrosine kinase (RYK), protein tyrosine kinase 7 (PTK7) and van gogh-like (VANGL1/2) [24]. Adding to this complexity, the Wnt response can differ depending on cell context and on the repertoire of Wnt receptors 
expressed $[25,26]$, further underlining the importance of determining the "Wnt status" of cells. ROR2, for example, has been shown to activate phosphatidylinositol-3 kinase (PI3K), which in turn activates JNK and its associated transcription factors c-Jun and ATF2 in Xenopus [27, 28]. Similarly, ROR1 activates the same signaling cascade to increase CREB phosphorylation in human breast cancer cells [29]. FZDs have been found to activate a number of additional intracellular effectors, including adenylate cyclase (AC), protein kinase A (PKA) and CREB [19], p38 and ATF2 [20] and Fyn and STAT3 [21]. In addition, a new $\beta$-catenin-independent aspect of Wnt signaling was recently reported in proliferating cells: Wnt signaling was found to peak at the G2/M phase of the cell cycle to produce so-called Wnt-dependent stabilization of proteins (Wnt/STOP) [30]. This appears to be a dominant mode of Wnt signaling in several cancer cell lines, where it is required for cell growth.

\section{Wnts and their receptors}

Although several Wnts preferentially activate either $\beta$-catenin-dependent (Wnt$1 / 3 a$ ) or $\beta$-catenin-independent (Wnt-5a/11) pathways, the activity of many Wnts is influenced by cellular context and the receptors available (LRPs versus RORs, for example) [31]. Traditionally FZD-LRP receptor-coreceptor combinations have been considered to be canonical, while RORs, RYK, PTK7 and VANGLs alone or in combination with FZDs have been associated with noncanonical Wnt signaling [31]. However, there are more than 15 different Wnt receptors and co-receptors, and the particular combination of these, together with a given Wnt, can affect subsequent signaling events [3]. Thus, Wnts and their receptors cannot be rigorously subdivided according to the pathway they induce in standard cell 
culture models.

Wnt proteins also compete with one another to give rise to different effects. Wnt5a, for example, preferentially activates PCP signaling and competes with Wnt-3a for binding to FZD2, thereby suppressing the $\beta$-catenin-dependent pathway [32]. An explanation for this promiscuity came from structural studies: the crystal structure of a complex between Xenopus Wnt-8 and the FZD8 cysteine-rich domain (CRD) reveals that the CRD directly binds Wnt-8 at two sites, one is the aminoterminal palmitoleic lipid that is present in all Wnt proteins, and the other is a conserved hydrophobic region in the Wnt carboxyl terminal domain. Although the palmitoleic anchorage site is also found in other FZD receptors, the second anchorage point is variable in sequence. As a result, different Wnt proteins may preferentially bind different FZD receptors [33]. Thus, it becomes clear that a Wnt protein has the potential to elicit many different cellular responses dictated by the availability of a panoply of receptors and intracellular effectors.

\section{Neural stem cells and their differentiation}

Neuronal differentiation is the process that neural stem cells (NSCs) undergo in order to become neurons. This process has been extensively studied both in developmental biology and stem cell biology. During the development of the nervous system, primitive cells act as a source of various types of specialized cells that make up the functioning brain. In addition, NSCs are important for adult neurogenesis, a process that, in mammals, takes place in the subventricular zone (SVZ) and in the subgranular zone (SGZ) of the hippocampus [34]. Although embryonic neurogenesis is likely to be less restricted anatomically, the maintenance, proliferation and neuronal fate commitment of local stem cell 
populations is regulated by signals from the microenvironment both in adults and embryos [35]. While much effort has been devoted to understanding the development of the central nervous system (CNS) in both the adult and embryonic settings, our understanding of the signals regulating differentiation remains incomplete. Many models have been developed to study these signaling cues. Embryonic stem (ES) cells, induced pluripotent stem (iPS) cells and even dental pulp stem cells [36] are being used to recapitulate differentiation. Those efforts serve not only to increase our understanding of the processes involved, but also may lead to new therapeutic applications. Cortical development has been extensively studied in the mouse embryo. In addition, adult neurogenesis, which was only accepted a decade ago [37], also provides a fantastic neurogenic model. The most important findings related to Wnt ligands and receptors in these models are summarized in Tables 1 and 2 respectively, but we will nevertheless discuss the findings of each model individually.

\section{Wnt signaling in the mouse brain}

All neurons of the mammalian neocortex ultimately originate from neuroepithelial cells (NECs), which are the cells that initially form the columnar monolayer epithelium, constituting the neural plate, and, subsequently, the pseudostratified epithelium that constitutes the early neural tube [38]. NECs initially undergo symmetric proliferative divisions in order to expand the population. After this initial amplification, cortical neurogenesis begins with single NECs switching to asymmetric differentiative cell division [39]. The asymmetric daughter cells then

either continue dividing as apical or basal progenitors or further undergo differentiation to become postmitotic neurons [38]. 
Through these symmetric and asymmetric expansions and differentiation, the cortex is shaped into a structure with a wide variety of neurons and glia, with highly stereotypical laminar arrangements and unique patterns of connectivity and function [40]. However, this is only a simplistic summary of a very complex process, of which only the stem cell aspect will be discussed here (see [41] for more details on developmental aspects).

Wnt signaling in the mouse brain: Wht ligands and receptors

There is no general consensus on the roles played by Wnt proteins during neurogenesis in the mouse brain, with different studies reporting different roles for the same Wnt ligand. In the nervous system, Wnt-3a knockout (KO) mice exhibit under-development of the hippocampus, as a result of a reduction in proliferation [42]. In contrast to this, ectopic expression of Wnt-3a induces the differentiation of intermediate cortical progenitors during mid- and late-cortical neurogenesis [43]. These contradictory findings show that one Wnt ligand can have different outputs depending in the cellular context: given that these molecules can compete with each other, other agonists and antagonists, and that they can interact with a wide range of receptors and co-receptors, it is not surprising that they can exert such different effects on developing cortical and hippocampal precursors.

Wnt-5a KO results in defects in dopaminergic neurogenesis and neurite development $[44,45]$, and Wnt-7a KO impairs maturation of dopaminergic and other neuronal populations [46-48](Table 1). While Wnt-3a has been described as canonical, Wnt-5a is generally associated with noncanonical Wnt signaling [49], and Wnt-7a is frequently found to play both canonical and noncanonical roles [50, 
51]. Bearing in mind that all these Wnts are required for the correct formation of the nervous system, and also that they often cooperate with one another [52], finetuning of canonical and noncanonical Wnt signals is likely to be necessary for neuronal development. In keeping with this, Wnt1/5a double KO (DKO) mice show exacerbated loss of dopaminergic neurons, when compared to Wnt5a KO mice, as described by Andersson et al. [52]. This elegant study also showed that mouse stem cells treated with both Wnt-3a and Wnt-5a produced more dopaminergic neurons, than cells treated with a single Wnt, providing further evidence for cooperation between noncanonical and canonical Wnts during dopaminergic differentiation, as suggested in an earlier study by the same group [53].

\begin{tabular}{|c|c|c|}
\hline Ligand & Neural phenotype in mammalian models & Reference \\
\hline Wnt-1 KO & $\begin{array}{l}\text { Altered central and peripheral neuronal } \\
\text { development during initial axonogenesis }\end{array}$ & {$[54]$} \\
\hline Wnt-1 KO & Impaired midbrain development & {$[55]$} \\
\hline $\begin{array}{l}\text { Wnt-1 dominant } \\
\text { negative }\end{array}$ & $\begin{array}{l}\text { Impaired hippocampal neurogenesis and spatial } \\
\text { and object recognition memory }\end{array}$ & {$[56,57]$} \\
\hline Wnt-1 overexpression & $\begin{array}{l}\text { Reduced neural differentiation of mESCs (also by } \\
\text { treatment with lithium chloride) }\end{array}$ & {$[58]$} \\
\hline Wnt-1 KO & $\begin{array}{l}\text { Increased differentiation into DA neurons in KO } \\
\text { mESCs }\end{array}$ & {$[59]$} \\
\hline Wnt-2 KO & $\begin{array}{l}\text { Decreased progenitor proliferation and } \\
\text { neurogenesis in the ventral midbrain }\end{array}$ & {$[60]$} \\
\hline Wnt-2 overexpression & $\begin{array}{l}\text { Induced dendritic arborization in hippocampal } \\
\text { progenitors }\end{array}$ & [61] \\
\hline Wnt-3 overexpression & Increased differentiation of cortical intermediate & [43] \\
\hline
\end{tabular}




\begin{tabular}{|c|c|c|}
\hline & progenitors & \\
\hline Wnt-3 overexpression & $\begin{array}{l}\text { Induced differentiation through cleavage of RYK } \\
\text { in cortical progenitors }\end{array}$ & [62] \\
\hline Wnt-3a KO & Loss of the hippocampus & [42] \\
\hline Recombinant Wnt-3a & $\begin{array}{l}\text { Induced GABAergic neuronal differentiation } \\
\text { through RYK, reduced oligodendrogenesis }\end{array}$ & [63] \\
\hline Recombinant Wnt-3a & Induced differentiation of hESCs & [64] \\
\hline $\begin{array}{l}\text { Recombinant/purified } \\
\text { Wnt-3a }\end{array}$ & Induced proliferation of hESCs/mNSCs & {$[65,66]$} \\
\hline Recombinant Wnt-3a & Induced proliferation and differentiation of hESCs & [67] \\
\hline Wnt-4 silencing & Impaired early differentiation in hECCs & [68] \\
\hline Wnt-5a KO & $\begin{array}{l}\text { Impaired neurite development in the olfactory } \\
\text { bulb (OB) }\end{array}$ & [44] \\
\hline $\begin{array}{l}\text { Wnt-1 and Wnt-5a } \\
\text { DKO }\end{array}$ & $\begin{array}{l}\text { Impaired neurogenesis of midbrain dopaminergic } \\
\text { neurons }\end{array}$ & [52] \\
\hline Wnt-5a KO & $\begin{array}{l}\text { Impaired axon growth and guidance of } \\
\text { dopaminergic neurons }\end{array}$ & [45] \\
\hline Wnt-5a CM & $\begin{array}{l}\text { Increased synaptogenesis and maturation of } \\
\text { hippocampal progenitors }\end{array}$ & {$[69,70]$} \\
\hline $\begin{array}{l}\text { Wnt-5a } \\
\text { overexpression }\end{array}$ & $\begin{array}{l}\text { Induced axonal differentiation in hippocampal } \\
\text { cultures }\end{array}$ & [71] \\
\hline Wnt-7a KO & $\begin{array}{l}\text { Delayed morphological maturation of } \\
\text { glomerular rosettes and synapsin I accumulation }\end{array}$ & [46] \\
\hline Wnt-7a KO & Impaired ventral midbrain neurogenesis & [47] \\
\hline Wnt-7a and Dvl DKO & $\begin{array}{l}\text { Defective spine morphogenesis and mossy fiber- } \\
\text { CA3 synaptic transmission }\end{array}$ & [48] \\
\hline Wnt-7a & $\begin{array}{l}\text { Proposed as a key element in the regulation of } \\
\text { NSC self-renewal/differentiation; altered spindle- }\end{array}$ & [72] \\
\hline
\end{tabular}




\begin{tabular}{l|l|l} 
Recombinant Wnt-7a & $\begin{array}{l}\text { size asymmetry during corticogenesis } \\
\text { Increased maturation and synaptogenesis of } \\
\text { hippocampal progenitors }\end{array}$ & {$[48]$} \\
$\begin{array}{l}\text { Recombinant Wnt-7b } \\
\text { Induced dendritic development in hippocampal } \\
\text { progenitors } \\
\text { overexpression }\end{array}$ & Maintenance of hEC-derived neural progenitors & {$[68]$} \\
\hline
\end{tabular}

Table 1. Wnt ligand effects on neural mammalian models. double-knockout, DKO; conditioned medium, CM.

Canonical Wnt receptors are also important for correct neural development (Table 2): FZD3 KO mice show impaired axonal guidance [73] while LRP6 KO mice present cortical defects [74]. Also, FZD1 has been shown to be the receptor for canonical Wnt-1 in mouse tyrosine hydroxylase positive neurons, which activates $\beta$-catenin-dependent signaling promoting neuroprotection in dopaminergic neurons [75].

Knocking out noncanonical receptors such as RYK, RORs and VANGLs results in defective axonal guidance and branching and neural tube defects [76-78]. Furthermore, cleavage of RYK is required for the effects of Wnt-3 on differentiation [62], resulting in an increase in the numbers of GABAergic neurons and inhibition of oligodendrogenesis [63]. It is interesting that a receptor such as RYK is able to bind Wnt-3, which has classically been described as a canonical Wnt that enhances stemness and proliferation. This highlights the promiscuous behavior of Wnt ligands and their ability to play multiple roles that likely depends on the availability of receptors and the intracellular machinery required to transduce different signals.

Finally, the noncanonical PCP pathway also plays a critical role in cortical 
development, since Wnt-7a and Vangl2 control spindle-size asymmetry during corticogenesis and are thus proposed to be key elements in the regulation of NSC self-renewal and differentiation [72, 79]. This is only natural if we take into account that the PCP pathway plays a very important role in asymmetry, and that asymmetric divisions are essential for stem and progenitor cells to ultimately shape the developing brain.

\begin{tabular}{|c|c|c|}
\hline Receptor & Neural phenotype in mammalian models & Reference \\
\hline \multirow[t]{2}{*}{ FZD1 } & Implicated in DAergic neuron survival & [80] \\
\hline & Implicated in synaptic organization & [81] \\
\hline FZD2 & $\begin{array}{l}\text { Mediates downregulation of differentiation in } \\
\text { mouse SVZ NSCs and gliomas by PLAGL2 }\end{array}$ & [82] \\
\hline \multirow[t]{3}{*}{ FZD3 } & Defective neural axon guidance in $\mathrm{KO}$ & [73] \\
\hline & Neural tube closure defect in FZD3/6 DKO & [83] \\
\hline & $\begin{array}{l}\text { Severe midbrain morphogenesis defects in } \\
\text { FZD3/6 DKO }\end{array}$ & {$[84]$} \\
\hline \multirow[t]{2}{*}{ FZD4 } & $\begin{array}{l}\text { Expressed in embryoid bodies and } \\
\text { downregulated upon differentiation of hESC }\end{array}$ & [85] \\
\hline & $\begin{array}{l}\text { Required for glioma stem cell stemness and } \\
\text { invasion }\end{array}$ & {$[86]$} \\
\hline \multirow[t]{4}{*}{ FZD5 } & $\begin{array}{l}\text { Expressed and down-regulated with } \\
\text { differentiation in mouse ES cells }\end{array}$ & [87] \\
\hline & $\begin{array}{l}\text { Down-regulated upon neural differentiation of } \\
\text { hESC }\end{array}$ & {$[88]$} \\
\hline & Down-regulated upon differentiation of iPS cells & [89] \\
\hline & $\begin{array}{l}\text { FZD5 CRD promotes neuroectodermal } \\
\text { differentiation }\end{array}$ & {$[90]$} \\
\hline \multirow[t]{3}{*}{ FZD6 } & $\begin{array}{l}\text { Severe midbrain morphogenesis defects in } \\
\text { FZD3/6 DKO }\end{array}$ & {$[84]$} \\
\hline & Neural tube closure defect in FZD3/6 DKO & [83] \\
\hline & $\begin{array}{l}\text { Labels rare, highly tumorigenic stem-like cells } \\
\text { in neuroblastoma }\end{array}$ & [91] \\
\hline \multirow[t]{2}{*}{ FZD7 } & Implicated in neural crest cell migration & {$[92]$} \\
\hline & Required for hEC cell proliferation & [93] \\
\hline
\end{tabular}




\begin{tabular}{|c|c|c|}
\hline & $\begin{array}{l}\text { FZD7 CRD promotes neuroectodermal } \\
\text { differentiation }\end{array}$ & [90] \\
\hline FZD8 & $\begin{array}{l}\text { FZD8 CRD promotes neuroectodermal } \\
\text { differentiation }\end{array}$ & [90] \\
\hline FZD9 & $\begin{array}{l}\text { KO mice show large increases in apoptotic cell } \\
\text { death in the developing dentate gyrus }\end{array}$ & [95] \\
\hline \multirow[t]{2}{*}{ VANGL1 } & Neural tube defects in KO mice & [96] \\
\hline & Neural tube defects in VANGL1/2 DKO mice & [78] \\
\hline \multirow[t]{4}{*}{ VANGL2 } & Neural tube defects in KO mice & [97] \\
\hline & Neural tube defects in VANGL1/2 DKO mice & [78] \\
\hline & $\begin{array}{l}\text { Causes precocious differentiation of neural } \\
\text { progenitors into early-born neurons }\end{array}$ & [79] \\
\hline & Regulates asymmetric division in mouse SVZ & [72] \\
\hline \multirow[t]{4}{*}{ ROR1/2 } & Implicated in neurite extension & [98] \\
\hline & Implicated in synapse formation & [99] \\
\hline & $\begin{array}{l}\text { Regulates differentiation in primary mouse } \\
\text { neural progenitors }\end{array}$ & [100] \\
\hline & Axon branching defect in ROR1/2 DKO mice & [77] \\
\hline \multirow[t]{3}{*}{ RYK } & Axon guidance defects in $\mathrm{KO}$ mice & [76] \\
\hline & Cleavage regulates neuronal differentiation & [62] \\
\hline & $\begin{array}{l}\text { Required for induction of GABAergic neurons \& } \\
\text { inhibition of oligodendrogenesis }\end{array}$ & [63] \\
\hline PTK7 & $\begin{array}{l}\text { Implicated in neural tube closure and } \\
\text { stereociliary bundle orientation }\end{array}$ & [101] \\
\hline \multirow[t]{2}{*}{ LRP4 } & $\begin{array}{l}\text { Required during the earliest events in the } \\
\text { postsynaptic neuromuscular junction }\end{array}$ & [102] \\
\hline & Required for neuromuscular synapse formation & [103] \\
\hline \multirow[t]{5}{*}{ LRP6 } & $\begin{array}{l}\text { Neural tube closure defects and mid/hindbrain } \\
\text { deficiencies in KO mice }\end{array}$ & [102] \\
\hline & $\begin{array}{l}\text { Disrupted production of dentate granule } \\
\text { neurons and radial glial scaffolding in KO mice }\end{array}$ & [104] \\
\hline & Cortical defects in KO mice & [74] \\
\hline & $\begin{array}{l}\text { Increased differentiation into DA neurons in KO } \\
\text { mESCs }\end{array}$ & [59] \\
\hline & Delayed DA neuron differentiation in KO mice & [105] \\
\hline
\end{tabular}


Table 2. Wnt receptor effects on neural mammalian models. DA,

dopaminergic; CRD, cysteine-rich domain; mESC, mouse embryonic stem cell.

Wnt signaling in the mouse brain: intracellular components

Several other transgenic mouse models have revealed clues about Wnt pathway components that are important for mouse brain development, many of them centered on the role of $\beta$-catenin-dependent canonical signaling. Ectopic expression of a $\beta$-catenin/LEF1 fusion protein, for example, activates canonical Wnt signaling in the developing cortex, promoting self-renewal and delaying expression of paired box 6 (PAX6), neurogenin 2 (NGN2) and eomesodermin (Tbr2) and subsequent neurogenesis. Several other reports showed that overexpression or activation of $\beta$-catenin expands the neuronal progenitor pool in the developing brain $[106,107]$, and expression of constitutively active $\beta$-catenin under the control of the GFAP promoter results in enlarged ventricles and an initial expansion of the PAX6-positive ventricular zone that is subsequently lost. Loss of PAX6 expression is not followed by expression of Tbr2, indicating that differentiation is impaired [108]. In keeping with these findings, conditional ablation of $\beta$-catenin accelerates expression of the previously mentioned neurogenic genes in a different study [109], and stabilization of Axin by the tankyrase inhibitor IWR-1 (which prevents $\beta$-catenin from signaling) reduces NSC proliferation in cortical neurospheres [110]. Thus, the importance of Wnt/ $\beta$ catenin signaling may lie in its role in maintaining neural stem/progenitor cell proliferation. While these studies support a role for $\beta$-catenin-dependent canonical Wnt signaling in stemness and proliferation, others support a role for $\beta$-catenin in 
differentiation: Hirabayashi et al. found that ectopic expression of $\beta$-catenin was able to drive the differentiation of mouse cortical progenitors, whereas the inhibition of canonical Wnt signaling prevented differentiation in the mouse neocortex [111]. This was confirmed by Munji et al., who showed that ectopic Wnt$3 a$ activates $\beta$-catenin in the mouse neocortex and leads to the differentiation of intermediate progenitors [43]. Interestingly, while the presence of cytoplasmic Axin is associated with proliferation of cortical intermediate progenitors, its phosphorylation leads to nuclear localization and $\beta$-catenin activation, which is required for differentiation in the mouse cortex [112]. While these studies support a role for $\beta$-catenin during differentiation, a very interesting study in cerebellar precursors by Pei et al. points out that while $\beta$-catenin overexpression induces cerebellar neural progenitor cell proliferation, it does not affect granule progenitor cells of embryonic and postnatal cerebellar origin [113]. These apparently contradictory findings suggest that $\beta$-catenin, like Wnts, can play multiple roles, in this case possibly through interaction with other transcription factors. Indeed, Israsena et al. have shown that overexpression of $\beta$-catenin in the presence of basic fibroblast growth factor 2 (bFGF) activates proliferation in mouse neural stem cells, while in its absence, $\beta$-catenin drives differentiation in the same cells [114]. Since bFGF promotes neural stem cell proliferation through MAP kinase signaling $[115,116]$, it is possible that interactions between intracellular components of these pathways result in different outcomes.

Several recent studies have focused on another interesting aspect of neural development related to canonical Wnt signaling, namely the role of the extracellular matrix. Targeted disruption of the gene encoding the Wnt co-receptor syndecan-1, for example, reduces $\beta$-catenin signaling and proliferation in neural 
progenitor cells [117]. Similar results were obtained in an unrelated study using Ncadherin mutant mice, where loss of $\mathrm{N}$-cadherin reduced $\beta$-catenin signaling and induced migration from the niche and differentiation [118]. An analogous situation was reported in the SVZ, where MT5-MMP was found to be the metalloproteinase that controls N-cadherin cleavage and subsequent activation of NSCs [119]. These reports highlight the potential importance of $\beta$-catenin signaling in regulating cell interactions in the stem cell niche and linking them to proliferation and stemness. Interactions with other cells or with the niche itself might also therefore influence the output of $\beta$-catenin signaling.

Disruption of noncanonical components, such as the transcription factors ATF2 and CREB, has also been associated with effects on cortical development [120, 121]. ATF2 deficient mice were shown to carry severe neurological abnormalities, with up to $50 \%$ of neuronal loss in the cerebellum [120]. Years later, Ackermann et al. were able to produce mice with a neuronal-specific ATF2 deletion that enabled its study in the CNS. Neuron-specific inactivation of ATF2 led to a significant loss of motor neurons in the brainstem; these developed normally but were unable to survive undergoing apoptosis. In this study it was proposed that ATF2 is required for correct motor neuron differentiation, and that it might achieve this by limiting the activity of stress kinases [122]. DKO mice for CREB and cyclic AMP response element modulatory protein (CREM) also show extensive neuronal loss as a result of increased apoptosis during neuronal development [121]. Together, these findings support a role for AP-1 family members during neuronal maturation.

\section{Wnt signaling and adult neurogenesis}


The discovery of neural stem/progenitor cells in the subventricular (SV) and subgranular (SG) zones of the adult CNS has changed our view of the brain from a static tissue to one that is dynamic and adaptive. Again, a complex process involving asymmetric division, expansion and differentiation of neural progenitors is necessary for correct hippocampal function [123], and so, as in the developing mouse brain, many studies have centered on studying the role of Wnt signaling in the hippocampus.

\section{Wnt signaling and adult neurogenesis: Wnt ligands and receptors}

The phenotype of Wnt-3a mutant mice (Table 1) highlights the essential role of Wnt signaling in the growth of the hippocampus. Wnt proteins secreted by hippocampal astrocytes promote proliferation in the hilus below the SGZ, a property that is lost in ageing mice $[56,124]$. Further evidence that Wnt-mediated neurogenesis contributes to adult hippocampal function comes from studies in which lentiviral expression of a dominant-negative form of Wnt-1 (dnWnt-1) was found to reduce neurogenesis, resulting in impaired long-term retention of spatial and object recognition memory $[56,57]$. Lie et al. reported that overexpression of Wnt3 is sufficient to induce differentiation from adult hippocampal progenitors in vitro and in vivo [56]. By contrast, blockade of canonical Wnt signaling using dnWnt-1 reduces differentiation in vitro and abolishes neurogenesis almost completely in vivo. These examples provide evidence that canonical Wnt ligands are essential for adult neurogenesis.

Noncanonical Wnt signaling has also been studied in hippocampal mouse models. In cultured hippocampal neurons, Wnt-5a activates a signaling cascade leading to activation of AP-1 [69] and increases dendritic spine morphogenesis [70]. Wnt-7a 
similarly increases dendritic spine density and maturity, albeit through a CAMKIIdependent mechanism [48]. On the other hand, knockout of the gene encoding Wnt-7a, results in a decrease in the numbers of newborn neurons in the SGZ and impairs their maturation, linking Wnt-7a both to self-renewal and differentiation [125]. The fact that canonical and noncanonical Wnt ligands, such as Wnt-7a, are required for correct neuronal production, suggests roles for both stimulation and repression of Wnt $/ \beta$-catenin signaling during neurogenesis. It is important to bear in mind, the coexistence of quiescent neural progenitors, amplifying neural progenitors, early differentiating neuroblasts, maturing neurons and granule cells in the hippocampus [126] can make it difficult to interpret results at the population level, since different cells may respond differently to proliferative and differentiative stimuli. The identity of the Wnt proteins involved in the SVZ is less clear; Wnt-7a is secreted by glial cells and promotes SVZ and olfactory bulb progenitor cell proliferation, and this has also been shown to be through a $\beta$ catenin-independent mechanism [127].

The roles of Wnt receptors in the hippocampus have also been investigated using mouse models. Knockout of FZD9 results in increased apoptosis in the developing dentate gyrus [95], and knockout of the Wnt co-receptor LRP6 disrupts production of dentate granule neurons and radial glial scaffolding [104]. Moreover, FZD5 transduces a noncanonical signal that establishes neuronal polarity [128], and ROR1 and ROR2 modulate synaptogenesis in hippocampal neurons [99].

The importance of secreted Wnt antagonists in neurogenesis should not be overlooked. Loss of Dickkopf-1 (Dkk-1), which normally inhibits Wnt/ $\beta$-catenin signaling by binding to LRP5/6, increases the number of neural progenitors in the 
hippocampus [129]. In addition, lentivirus-mediated knockdown of the Wnt antagonist secreted frizzled related protein 3 (sFRP3 or FRZB) in the dentate gyrus increases canonical Wnt signaling, neural progenitor proliferation and neuronal development [130]. These observations suggest that secreted Wnt antagonists promote functional homeostasis in the niche during adult neurogenesis. Abnormal activation of the stem cell niche leads to NSC depletion, so soluble Wnt antagonists could be among the factors that prevent excessive activation of the stem cell population, which would have detrimental effects.

\section{Wnt signaling and adult neurogenesis: intracellular components}

Many different approaches have been used to study the effects of altering canonical Wnt signaling in the mouse hippocampus. The FZD8 CRD, which inhibits Wnt signaling, increases the numbers of neurons and leads to a concomitant depletion of the multipotent progenitor cell population [131], while the GSK-3 $\beta$ inhibitor lithium chloride ( $\mathrm{LiCl}$ ), which stabilizes and activates $\beta$-catenin, induces adult hippocampal progenitor cell proliferation [132]. LiCl treatment also stimulates cell proliferation and neuronal fate specification in a mouse model of Alzheimer's disease [133]. Conditional knockout of APC in GFAP-expressing cells of mice activates $\beta$-catenin, reduces neurogenesis and impairs neuronal differentiation [134]. However, it is worth noting that while $\mathrm{LiCl}$ and APC gene deletion both activate $\beta$-catenin signaling, these treatments have unrelated $\beta$ catenin-independent effects [135-138]. APC, for example, also plays a role in neuronal migration by binding the $3^{\prime}$ UTR of $\beta 2 B-t u b u l i n$ mRNA [139]. Nevertheless, studies generally point towards a role for $\mathrm{Wnt} / \beta$-catenin signaling in stemness and proliferation in the hippocampus. 
Numerous studies have also reported roles for Wnt signaling in the SVZ. $\beta$ catenin-responsive cells exist in the SVZ throughout the development of the CNS [140], and their activation promotes progenitor cell proliferation [141]. Activation of $\beta$-catenin signaling increases the numbers of oligodendrocytes derived from this neurogenic site, while inhibition seems to reduce the glial cell number [142]. In another study, $\beta$-catenin activation via GSK-3 inhibition increased cell proliferation in the SVZ, and this was accompanied by increased numbers of oligodendrocytes [143], confirming an earlier study that highlighted oligodendrocytic genes as targets of $\beta$-catenin [144]. Thus, Wnt/ $\beta$-catenin signaling may also play important roles in the proliferation of progenitors and in oligodendrocytic development in the SVZ.

However, there is also evidence that supports roles for noncanonical downstream effectors in this context. As noted earlier, AP-1 family members are regulated by JNK family protein kinases. Mice lacking JNK1, JNK2 or JNK3 perform less well than their wild-type littermates in several behavioral tasks, including the elevated plus maze, open field, novel object recognition memory test and Morris water maze [145]. Moreover, injection of the JNK inhibitor SP600125 into the mouse hippocampus reduces long-term memory [146]. On the other hand, expression of a dominant-negative form of CREB, which blocks the activity of all CREB heterodimers, disrupts hippocampus-dependent spatial memory [147]. Moreover, hippocampal granule cell proliferation is increased by activation of cAMP signaling and reduced by CREB inhibition [148], and combined disruption of CREB and CREM leads to neurodegeneration in the hippocampus and in the dorsolateral striatum [121]. In contrast, conditional knockout of c-Jun using the Nestin gene 
promoter does not affect hippocampal-dependent behavior or brain morphology [149], but greatly impairs axonal regeneration, supporting a role for this AP-1 family member in neuronal maturation. ATF2 is also found in the human hippocampus and its expression is reduced in patients with Parkinson's and Alzheimer's disease [89]. These studies highlight the relevance of JNK and AP-1 family members for adult neurogenesis. Since the loss of neurons in the hippocampus is linked to several neurodegenerative diseases [90], further studies of Wnt/AP-1 signaling in this niche are warranted.

\section{Human neural stem and progenitor cells}

Unlike conventional cell lines, human ES- and iPS-derived neural stem cells are not transformed and resemble primary NSC cultures, thus providing good models for studying human NSC differentiation $[115,150,151]$. In addition, the unique developmental potential and replicative capacity of these cells offers an abundant source of specific somatic cell types that can be exploited for in vitro mechanistic studies and cell transplantation therapies. However, in order to obtain human neural progenitor (hNP) cells, hES cells and iPS cells need to be oriented towards the neural lineage. To do so, hES cells, normally cultured as embryoid bodies $[115$, 152], are placed in stringent serum-free culture conditions that selectively facilitate the survival and growth of neural cells [153]. CHIR99021 has been widely used in order to keep cells in an undifferentiated and proliferative state in order to initially increase neural progenitor cell number, and ultimately neuronal yield [16, 154-156]. When the cells enter the neural lineage, rosette-like structures appear. These structures resemble the cellular organization of the neural tube [157] and can be mechanically selected in order to increase their numbers. Growth factors, 
normally bFGF and leukemia inhibitory factor (LIF) are used to maintain these cells in a state of self-renewal [107], such that they retain the expression of NSC markers, such as Nestin and SOX2, and can be induced to differentiate into neurons upon withdrawal of bFGF.

\section{Human neural stem and progenitor cells: Wht ligands and receptors}

Wnt signals can affect neuronal differentiation of hES- and iPS-derived NSCs [16, $131,158]$, but there are conflicting reports in the literature on the signaling pathways involved. Canonical Wnt-3a has been shown to stimulate differentiation when added exogenously to hES cell cultures [67]. In keeping with these findings, differentiation of neural rosette progeny in the presence of Wnt-3a leads to the induction of markers compatible with ventral forebrain fate and the emergence of GABA+ neurons and cells expressing dorsal markers [159]. On the other hand, exogenous Wnt-3a was shown to support the expansion and maintenance of hES cells [65]. In mES cells, the secreted Wnt antagonist sFRP2 stimulates production of neural progenitors [58]. In the same study, activation by canonical Wnt-1 and LiCl blocked differentiation, supporting a model in which inhibition of canonical Wnt signaling is required for neuronal differentiation.

Less is known about the role of noncanonical Wnt signaling. Wnt-11, a noncanonical Wnt, promotes stem cell differentiation in several contexts [160]. For example, it induces hES cell exit from the pluripotent state, mesodermal/hematopoietic cell fate [161] and cardiac differentiation of mES cells [162]. In human embryonal carcinoma cells, Wnt-11 maintains neural progenitor cell proliferation but prevents further differentiation, which instead is driven by another noncanonical Wnt, Wnt-4 [68]. We recently found that noncanonical Wnt- 
3a signaling stimulates differentiation of hES cells and iPS cells, something that could account for some of the controversy found in the literature regarding the role of Wnt-3a [163]. The nature of the response to Wnt-3a, canonical versus noncanonical, are likely to be influenced by the relative levels of Wnt receptors, secreted Wnt antagonists and intracellular effectors expressed by target cells. Comprehensive approaches that take these factors into account will be required for a complete understanding of how Wnt signals drive neurogenesis.

\section{Human neural stem and progenitor cells: intracellular components}

Again, controversial studies have been published on the role of canonical downstream components of Wnt signaling in this field. Many studies provide evidence that canonical Wnt signaling drives neuronal differentiation. Davidson et al. reported that $\beta$-catenin signaling is repressed by Oct 4 in hES cells, and that activation of $\beta$-catenin promotes differentiation [64]. In another study, recombinant Wnt-3a stimulated both proliferation and differentiation of hES cells. Canonical $\beta$-catenin/Tcf-dependent transcriptional activity was found to be elevated in the differentiating cells, suggesting that canonical activity supports differentiation [67]. However, many other reports highlight the role of canonical Wnt signaling in stem/progenitor cell maintenance, rather than induction of differentiation. For example, Wexler et al. showed that baseline $\beta$-catenin signaling represses neuronal differentiation in human NSCs [131], and another study reported that inhibition of Wnt/ $\beta$-catenin signaling using Dkk-1 or the tankyrase inhibitor XAV939 promotes neural precursor specification [164]. Moreover, GSK-3 inhibition, which induces stem cell renewal and sustains the expression of pluripotency markers [16], is a widely used tool to expand neural progenitors 
[154-156], and bFGF treatment of hES and iPS cells, which maintains the undifferentiated state, activates canonical Wnt signaling through inhibition of GSK3 [165].

There are also conflicting reports from studies using mES cells. Again, some emphasize the importance of canonical Wnt signaling for differentiation [166, 167], while others suggest the opposite [59, 168-170]. This could be partially explained by the fact that the culture conditions used vary, and that NSCs and neural progenitors are very general terms. Thorough characterization of each cellular model is therefore necessary to link any findings to their particular context. Whatever the conclusions drawn, studies to date highlight the importance of tight control of Wnt/ $\beta$-catenin signaling during neuronal differentiation. It might very well be the case that canonical and noncanonical Wnt signaling are required at different time points and even cooperate in order to promote stem cell maintenance and/or differentiation.

More recently, mES cell differentiation was found to be accompanied by activation of noncanonical signaling via increased expression of Tcf3 [171], which is known to signal independently of $\beta$-catenin in several contexts [172]. This is consistent with our findings in human NSCs, where Wnt-3a promotes differentiation via JNK/ATF2 independently of $\beta$-catenin [163], and with a recent study in human iPS cells, which showed that Wnt-3 and Wnt-9B cooperate to promote dopaminergic differentiation, with canonical signaling maintaining proliferation and noncanonical signaling, involving JNK, driving differentiation [173]. These studies indicate that noncanonical signaling can play an important role during the differentiation of hES cells and warrant further studies of noncanonical Wnt 
signals to shed light on the process.

Wnt signals also interact with other pathways. Li et al. showed that endogenous Wht signaling in hES cells upregulates the truncated form of GLI3, a repressor of sonic hedgehog $(\mathrm{SHH})$, producing dorsal telencephalic neural progenitors. A high concentration of $\mathrm{SHH}$, or the inhibition of Wnt by Dkk-1 together with a low concentration of $\mathrm{SHH}$, almost completely converted primitive dorsal precursors to ventral progenitors. These dorsal and ventral telencephalic progenitors later differentiate to functional glutamatergic and GABAergic neurons, respectively [174]. Indeed, midbrain progenitors, which can express both floor and roof plate markers, are enriched when hES cells were treated with both SHH and Wnt activators [154]. Crosstalk between pathways such as these plays central roles in neuronal specification and so is critical for cell therapy oriented studies. Given that individual Wnts are likely to have different impacts on other pathways and thus on self-renewal and differentiation (Fig. 3), comprehensive studies are required to clarify existing controversies in the field.

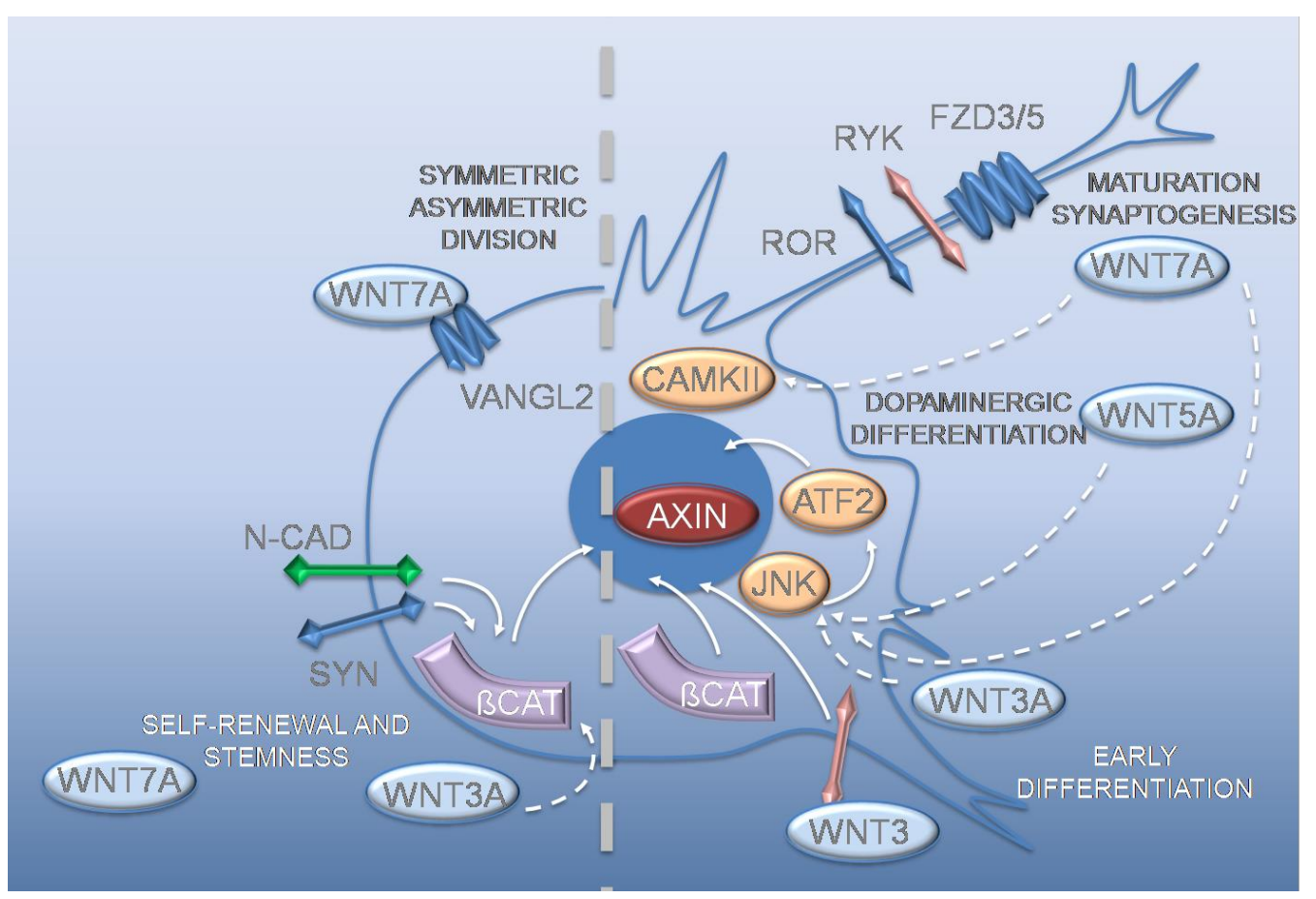


Figure 3. Canonical and Noncanonical Wnt signaling in neural stem cells. Both aspects of Wnt signaling play important roles in NSC maintenance, differentiation and maturation. Wnt-3a and Wnt-7a are able to activate both canonical and noncanonical signals and so induce proliferation or differentiation and maturation, respectively; $\mathrm{N}$-cadherin, $\mathrm{N}-\mathrm{CAD}$.

\section{Conclusions}

Previous studies highlight the critical role Wnt signaling plays in NSCs, but the nature of the Wnt signals involved remains unclear, with reports of increased and decreased Wnt signaling taking place during differentiation $[68,175]$ and disease $[176,177]$. Neurogenesis in the hippocampus, where Wnt signaling plays important roles, is gradually lost as we age [178], and this loss is implicated in neurodegenerative diseases [123]. Furthermore, Wnt signaling has been implicated in other neurodegenerative events, such as impaired myelination and loss of dopaminergic neurons $[177,179]$. It is also important to note that, given its complexity, Wnt signaling is likely to play many different roles that will depend on the identities of the ligands, receptors and effectors that expressed by the stem cells themselves and by cells in their niche. Global approaches will be required to identify and interrogate the functions of the key components that promote differentiation. This information can then be used to identify those changes that have an impact on disease and aging, and to optimize methods to generate neurons for stem cell-based therapies. In addition, further studies are warranted to determine the impact of Wnt signaling on cell physiology at the point of cell harvest and at cell implantation at sites of injury. While the results of these studies are anticipated to be important from a biomedical perspective, many basic key questions remain unanswered. What roles do Wnt signals play in the neural stem 
cell niche? Are Wnt proteins important for neuro-immune interactions during inflammation-directed brain repair? Do Wnt signals control glial/neuronal progenitor signaling crosstalk? How is Wnt ligand expression regulated? Recent studies are beginning to provide answers [80, 180-182]. Nevertheless, further work will be essential to understand how Wnt signals are coordinated during the generation, expansion and differentiation of neurons, and apply this knowledge to optimize stem cell-based therapies.

\section{Bibliography}

1. MacDonald BT, Tamai K, He X (2009) Wnt/beta-catenin signaling: components, mechanisms, and diseases. Dev Cell 17:9-26. doi: 10.1016/j.devcel.2009.06.016

2. Clevers H, Nusse R (2012) Wnt/ $\beta$-Catenin Signaling and Disease. Cell 149:1192-1205. doi: 10.1016/j.cell.2012.05.012

3. Niehrs C (2012) The complex world of WNT receptor signalling. Nat Rev Mol Cell Biol 13:767-79. doi: 10.1038/nrm3470

4. Li VSW, Ng SS, Boersema PJ, et al. (2012) Wnt signaling through inhibition of $\beta$-catenin degradation in an intact Axin1 complex. Cell 149:1245-56. doi: 10.1016/j.cell.2012.05.002

5. Kawano Y, Kypta R (2003) Secreted antagonists of the Wnt signalling pathway. J Cell Sci 116:2627-2634. doi: 10.1242/jcs.00623

6. Xavier CP, Melikova M, Chuman Y, et al. (2014) Secreted Frizzled-related protein potentiation versus inhibition of Wnt3a/ $\beta$-catenin signaling. Cell Signal 26:94-101. doi: 10.1016/j.cellsig.2013.09.016

7. Satoh S, Daigo Y, Furukawa Y, et al. (2000) AXIN1 mutations in hepatocellular carcinomas, and growth suppression. Nat Genet 24:245-250.

8. Lammi L, Arte S, Somer M, et al. (2004) Mutations in AXIN2 cause familial tooth agenesis and predispose to colorectal cancer. Am J Hum Genet 74:1043-50. doi: 10.1086/386293 
9. Nishisho I, Nakamura Y, Miyoshi Y, et al. (1991) Mutations of chromosome $5 q 21$ genes in FAP and colorectal cancer patients. Sci 253 :665-669. doi: 10.1126/science. 1651563

10. Morin PJ, Sparks AB, Korinek V, et al. (1997) Activation of $\beta$-Catenin-Tcf Signaling in Colon Cancer by Mutations in $\beta$-Catenin or APC. Sci $275: 1787-$ 1790. doi: $10.1126 /$ science. 275.5307 .1787

11. Takeda H, Lyle S, Lazar AJF, et al. (2006) Human sebaceous tumors harbor inactivating mutations in LEF1. Nat Med 12:395-397.

12. Bass AJ, Lawrence MS, Brace LE, et al. (2011) Genomic sequencing of colorectal adenocarcinomas identifies a recurrent VTI1A-TCF7L2 fusion. Nat Genet 43:964-968.

13. Chen B, Dodge ME, Tang W, et al. (2009) Small molecule-mediated disruption of Wnt-dependent signaling in tissue regeneration and cancer. Nat Chem Biol 5:100-107.

14. Proffitt K, Madan B, Ke Z, et al. (2013) Pharmacological inhibition of the Wnt acyltransferase PORCN prevents growth of WNT-driven mammary cancer. Cancer Res 73:502-7.

15. Huang S-M a, Mishina YM, Liu S, et al. (2009) Tankyrase inhibition stabilizes axin and antagonizes Wnt signalling. Nature 461:614-620. doi: $10.1038 /$ nature08356

16. Sato N, Meijer L, Skaltsounis L, et al. (2004) Maintenance of pluripotency in human and mouse embryonic stem cells through activation of Wnt signaling by a pharmacological GSK-3-specific inhibitor. Nat Med 10:55-63. doi: $10.1038 / \mathrm{nm} 979$

17. Gonsalves FC, Klein K, Carson BB, et al. (2011) An RNAi-based chemical genetic screen identifies three small-molecule inhibitors of the Wnt/wingless signaling pathway. Proc Natl Acad Sci 108:5954-5963.

18. Van Amerongen R, Nusse R (2009) Towards an integrated view of Wnt signaling in development. Development 136:3205-3214.

19. Gómez-Orte E, Sáenz-Narciso B, Moreno S, Cabello J (2013) Multiple functions of the noncanonical Wnt pathway. Trends Genet 29:545-53. doi: 10.1016/j.tig.2013.06.003

20. Lopez-Bergami P, Lau E, Ronai Z (2010) Emerging roles of ATF2 and the dynamic AP1 network in cancer. Nat Rev Cancer 10:65-76.

21. Kohn AD, Moon RT (2005) Wnt and calcium signaling: beta-cateninindependent pathways. Cell Calcium 38:439-446. 
22. Rao TP, Kühl M (2010) An updated overview on Wnt signaling pathways: a prelude for more. Circ Res 106:1798-806. doi:

10.1161/CIRCRESAHA.110.219840

23. De A (2011) Wnt / Ca2 + signaling pathway : a brief overview The Noncanonical Wnt Signaling Cascade. 43:745-756. doi: 10.1093/abbs/gmr079

24. Clark CEJ, Nourse CC, Cooper HM (2012) The tangled web of non-canonical Wnt signalling in neural migration. Neurosignals 20:202-20. doi: $10.1159 / 000332153$

25. Yu H, Ye X, Guo N, Nathans J (2012) Frizzled 2 and frizzled 7 function redundantly in convergent extension and closure of the ventricular septum and palate: evidence for a network of interacting genes. Development 139:4383-94.

26. Najdi R, Proffitt K, Sprowl S, et al. (2012) A uniform human Wnt expression library reveals a shared secretory pathway and unique signaling activities. Differ Res Biol Divers 1-11. doi: 10.1016/j.diff.2012.06.004

27. Schambony A, Wedlich D (2007) Wnt-5A/Ror2 regulate expression of XPAPC through an alternative noncanonical signaling pathway. Dev Cell 12:779-92. doi: 10.1016/j.devcel.2007.02.016

28. Liu Y, Rubin B, Bodine PVN, Billiard J (2008) Wnt5a induces homodimerization and activation of Ror2 receptor tyrosine kinase. J Cell Biochem 105:497-502. doi: 10.1002/jcb.21848

29. Zhang S, Chen L, Cui B, et al. (2012) ROR1 is expressed in human breast cancer and associated with enhanced tumor-cell growth. PLoS One 7:e31127. doi: 10.1371/journal.pone.0031127

30. Acebron SP, Karaulanov E, Berger BS, et al. (2014) Mitotic wnt signaling promotes protein stabilization and regulates cell size. Mol Cell 54:663-74. doi: 10.1016/j.molcel.2014.04.014

31. Grumolato L, Liu G, Mong P, et al. (2010) Canonical and noncanonical Wnts use a common mechanism to activate completely unrelated coreceptors. Genes Dev.

32. Sato A, Yamamoto H, Sakane H, et al. (2010) Wnt5a regulates distinct signalling pathways by binding to Frizzled2. EMBO J 29:41-54. doi: 10.1038/emboj.2009.322

33. Janda CY, Waghray D, Levin AM, et al. (2012) Structural basis of Wnt recognition by Frizzled. Science (80- ) 337:59-64. doi: 10.1126/science.1222879 
34. Aimone JB, Deng W, Gage FH (2010) Adult neurogenesis: integrating theories and separating functions. Trends Cogn Sci 14:325-337.

35. Nusse R (2008) Wnt signaling and stem cell control. Cell Res 18:523-7. doi: $10.1038 / \mathrm{cr} .2008 .47$

36. Young F, Sloan A, Song B (2013) Dental pulp stem cells and their potential roles in central nervous system regeneration and repair. J Neurosci Res 91:1383-93. doi: 10.1002/jnr.23250

37. Gage FH (2002) Neurogenesis in the adult brain. J Neurosci 22:612-3.

38. Florio M, Huttner WB (2014) Neural progenitors, neurogenesis and the evolution of the neocortex. Development 141:2182-94. doi: 10.1242/dev.090571

39. Götz M, Huttner WB (2005) The cell biology of neurogenesis. Nat Rev Mol Cell Biol 6:777-88. doi: 10.1038/nrm1739

40. Bartolini G, Ciceri G, Marín O (2013) Integration of GABAergic interneurons into cortical cell assemblies: lessons from embryos and adults. Neuron 79:849-64. doi: 10.1016/j.neuron.2013.08.014

41. Bielen H, Houart C (2014) The Wnt cries many: Wnt regulation of neurogenesis through tissue patterning, proliferation, and asymmetric cell division. Dev Neurobiol 74:772-780. doi: 10.1002/dneu.22168

42. Lee SM, Tole S, Grove E, McMahon a P (2000) A local Wnt-3a signal is required for development of the mammalian hippocampus. Development 127:457-67.

43. Munji RN, Choe Y, Li G, et al. (2011) Wnt signaling regulates neuronal differentiation of cortical intermediate progenitors. J Neurosci 31:16761687. doi: 10.1523/JNEUROSCI.5404-10.2011

44. Pino D, Choe Y, Pleasure SJ (2011) Wnt5a controls neurite development in olfactory bulb interneurons. Am Soc Neurochem 3:125-133. doi: 10.1042/AN20100038

45. Blakely BD, Bye CR, Fernando C V, et al. (2011) Wnt5a regulates midbrain dopaminergic axon growth and guidance. PLoS One 6:e18373. doi: 10.1371/journal.pone.0018373

46. Hall AC, Lucas FR, Salinas PC, et al. (2000) Axonal Remodeling and Synaptic Differentiation in the Cerebellum Is Regulated by WNT-7a Signaling King ' $s$ College London. 100:525-535. 
47. Fernando CV, Kele J, Bye CR, et al. (2014) Diverse Roles for Wnt7a in Ventral Midbrain Neurogenesis and Dopaminergic Axon Morphogenesis. Stem Cells Dev 23:1991-2003.

48. Ciani L, Boyle KA, Dickins E, et al. (2011) Wnt7a signaling promotes dendritic spine growth and synaptic strength through Ca2+/Calmodulindependent protein kinase II. Proc Natl Acad Sci. doi: $10.1073 /$ pnas. 1018132108

49. Many AM, Brown AMC (2014) Both canonical and non-canonical Wnt signaling independently promote stem cell growth in mammospheres. PLoS One 9:e101800. doi: 10.1371/journal.pone.0101800

50. Davis EK, Zou Y, Ghosh A (2008) Wnts acting through canonical and noncanonical signaling pathways exert opposite effects on hippocampal synapse formation. Neural Dev 3:32. doi: 10.1186/1749-8104-3-32

51. Rosso SB, Sussman D, Wynshaw-Boris A, Salinas PC (2005) Wnt signaling through Dishevelled, Rac and JNK regulates dendritic development. Nat Neurosci 8:34-42. doi: 10.1038/nn1374

52. Andersson ER, Saltó C, Villaescusa JC, et al. (2012) Wnt5a cooperates with canonical Wnts to generate midbrain dopaminergic neurons in vivo and in stem cells. Proc Natl Acad Sci. doi: 10.1073/pnas.1208524110//DCSupplemental.www.pnas.org/cgi/doi/10.1073/pnas.1208524110

53. Castelo-Branco G, Wagner J, Rodriguez FJ, et al. (2003) Differential regulation of midbrain dopaminergic neuron development by Wnt-1, Wnt3a, and Wnt-5a. Proc Natl Acad Sci 100:12747-12752. doi: 10.1073/pnas. 1534900100

54. Shimamura K, Hirano S, McMahon a P, Takeichi M (1994) Wnt-1-dependent regulation of local E-cadherin and alpha $\mathrm{N}$-catenin expression in the embryonic mouse brain. Development 120:2225-34.

55. McMahon AP, Joyner AL, Bradley A, McMahon JA (1992) The midbrainhindbrain phenotype of Wnt-1-Wnt-1- mice results from stepwise deletion of engrailed-expressing cells by 9.5 days postcoitum. Cell 69:581-595. doi: 10.1016/0092-8674(92)90222-X

56. Lie D-C, Colamarino S a, Song H-J, et al. (2005) Wnt signalling regulates adult hippocampal neurogenesis. Nature 437:1370-5. doi: 10.1038/nature04108

57. Jessberger S, Clark RE, Broadbent NJ, et al. (2009) Dentate gyrus-specific knockdown of adult neurogenesis impairs spatial and object recognition memory in adult rats. Learn Mem 16:147-54. doi: 10.1101/lm.1172609 
58. Aubert J, Dunstan H, Chambers I, Smith A (2002) Functional gene screening in embryonic stem cells implicates Wnt antagonism in neural differentiation. Nat Biotechnol 20:1240-5. doi: 10.1038/nbt763

59. Cajánek L, Ribeiro D, Liste I, et al. (2009) Wnt/beta-catenin signaling blockade promotes neuronal induction and dopaminergic differentiation in embryonic stem cells. Stem Cells 27:2917-27. doi: 10.1002/stem.210

60. Sousa KM, Carlos Villaescusa J, Cajanek L, et al. (2010) Wnt2 regulates progenitor proliferation in the developing ventral midbrain. J Biol Chem 285:7246-7253. doi: 10.1074/jbc.M109.079822

61. Wayman G a., Impey S, Marks D, et al. (2006) Activity-Dependent Dendritic Arborization Mediated by CaM-Kinase I Activation and Enhanced CREBDependent Transcription of Wnt-2. Neuron 50:897-909. doi: 10.1016/j.neuron.2006.05.008

62. Lyu J, Yamamoto V, Lu W (2008) Cleavage of the Wnt receptor Ryk regulates neuronal differentiation during cortical neurogenesis. Dev Cell 15:773-80. doi: 10.1016/j.devcel.2008.10.004

63. Zhong J, Kim H-T, Lyu J, et al. (2011) The Wnt receptor Ryk controls specification of GABAergic neurons versus oligodendrocytes during telencephalon development. Development 138:409-19. doi: 10.1242/dev.061051

64. Davidson KC, Adams AM, Goodson JM, et al. (2012) Wnt/ $\beta$-catenin signaling promotes differentiation, not self-renewal, of human embryonic stem cells and is repressed by Oct4. Proc Natl Acad Sci 109:4485-90. doi: $10.1073 /$ pnas. 1118777109

65. Davidson KC, Jamshidi P, Daly R, et al. (2007) Wnt3a regulates survival, expansion, and maintenance of neural progenitors derived from human embryonic stem cells. Mol Cell Neurosci 36:408-415.

66. Kalani MYS, Cheshier SH, Cord BJ, et al. (2008) Wnt-mediated self-renewal of neural stem/progenitor cells. Proc Natl Acad Sci 105:16970-16975.

67. Dravid G, Ye Z, Hammond H, et al. (2005) Defining the role of Wnt/betacatenin signaling in the survival, proliferation, and self-renewal of human embryonic stem cells. Stem Cells 23:1489-501. doi: 10.1634/stemcells.2005-0034

68. Elizalde C, Campa VM, Caro M, et al. (2011) Distinct roles for Wnt-4 and Wnt11 during retinoic acid-induced neuronal differentiation. Stem Cells 29:141153. doi: $10.1002 /$ stem.562 
69. Farías GG, Alfaro IE, Cerpa W, et al. (2009) Wnt-5a/JNK signaling promotes the clustering of PSD-95 in hippocampal neurons. J Biol Chem 284:1585766. doi: $10.1074 /$ jbc.M808986200

70. Varela-Nallar L, Alfaro IE, Serrano FG, et al. (2010) Wingless-type family member 5A (Wnt-5a) stimulates synaptic differentiation and function of glutamatergic synapses. Proc Natl Acad Sci 107:21164-21169. doi: 10.1073/pnas.1010011107/

71. Zhang X, Zhu J, Yang G-Y, et al. (2007) Dishevelled promotes axon differentiation by regulating atypical protein kinase C. Nat Cell Biol 9:743754. doi: $10.1038 /$ ncb1603

72. Delaunay D, Cortay V, Patti D, et al. (2014) Mitotic spindle asymmetry: a Wnt/PCP-regulated mechanism generating asymmetrical division in cortical precursors. Cell Rep 6:400-14. doi: 10.1016/j.celrep.2013.12.026

73. Wang Y, Thekdi N, Smallwood PM, et al. (2002) Frizzled-3 is required for the development of major fiber tracts in the rostral CNS. J Neurosci 22:8563-73.

74. Zhou C, Borello U, Rubenstein JLR (2006) Neuronal production and precursor proliferation defects in the neocortex of mice with loss of function in the canonical Wnt signaling pathway. Neuroscience 142:1119-1131. doi: 10.1016/j.neuroscience.2006.07.007

75. L'episcopo F, Serapide MF, Tirolo C, et al. (2011) A Wnt1 regulated Frizzled$1 / \beta$-Catenin signaling pathway as a candidate regulatory circuit controlling mesencephalic dopaminergic neuron-astrocyte crosstalk: Therapeutical relevance for neuron survival and neuroprotection. Mol Neurodegener 6:49. doi: 10.1186/1750-1326-6-49

76. Lu W, Yamamoto V, Ortega B, Baltimore D (2004) Mammalian Ryk is a Wnt coreceptor required for stimulation of neurite outgrowth. Cell 119:97-108. doi: 10.1016/j.cell.2004.09.019

77. Ho H-YH, Susman MW, Bikoff JB, et al. (2012) Wnt5a-Ror-Dishevelled signaling constitutes a core developmental pathway that controls tissue morphogenesis. Proc Natl Acad Sci 109:4044-51. doi: 10.1073/pnas.1200421109

78. Torban E, Patenaude A-M, Leclerc S, et al. (2008) Genetic interaction between members of the Vangl family causes neural tube defects in mice. Proc Natl Acad Sci 105:3449-54. doi: 10.1073/pnas.0712126105

79. Lake BB, Sokol SY (2009) Strabismus regulates asymmetric cell divisions and cell fate determination in the mouse brain. J Cell Biol 185:59-66. doi: $10.1083 /$ jcb.200807073 
80. Marchetti B, L'Episcopo F, Morale MC, et al. (2013) Uncovering novel actors in astrocyte-neuron crosstalk in Parkinson's disease: the Wnt/ $\beta$-catenin signaling cascade as the common final pathway for neuroprotection and selfrepair. Eur J Neurosci 37:1550-63. doi: 10.1111/ejn.12166

81. Inestrosa NC, Arenas E (2010) Emerging roles of Wnts in the adult nervous system. Nat Rev Neurosci 11:77-86. doi: 10.1038/nrn2755

82. Zheng $\mathrm{H}$, Ying $\mathrm{H}$, Wiedemeyer $\mathrm{R}$, et al. (2010) PLAGL2 regulates Wnt signaling to impede differentiation in neural stem cells and gliomas. Cancer Cell 17:497-509. doi: 10.1016/j.ccr.2010.03.020

83. Wang Y, Guo N, Nathans J (2006) The role of Frizzled3 and Frizzled6 in neural tube closure and in the planar polarity of inner-ear sensory hair cells. J Neurosci 26:2147-56. doi: 10.1523/JNEUROSCI.4698-05.2005

84. Stuebner S, Faus-Kessler T, Fischer T, et al. (2010) Fzd3 and Fzd6 deficiency results in a severe midbrain morphogenesis defect. Dev Dyn 239:246-60. doi: $10.1002 /$ dvdy.22127

85. Bethea CL, Reddy AP, Pedersen D, Tokuyama Y (2009) Gene Expression Patterns Expression profile of differentiating serotonin neurons derived from rhesus embryonic stem cells and comparison to adult serotonin neurons q. Gene Expr Patterns 9:94-108. doi: 10.1016/j.gep.2008.10.002

86. Jin X, Jeon H-Y, Joo KM, et al. (2011) Frizzled 4 regulates stemness and invasiveness of migrating glioma cells established by serial intracranial transplantation. Cancer Res 71:3066-75. doi: 10.1158/0008-5472.CAN-101495

87. Verani R, Cappuccio I, Spinsanti P, et al. (2007) Expression of the Wnt inhibitor Dickkopf-1 is required for the induction of neural markers in mouse embryonic stem cells differentiating in response to retinoic acid. J Neurochem 100:242-50. doi: 10.1111/j.1471-4159.2006.04207.x

88. Wu JQ, Habegger L, Noisa P, et al. (2010) Dynamic transcriptomes during neural differentiation of human embryonic stem cells revealed by short, long, and paired-end sequencing. Proc Natl Acad Sci 107:5254-9. doi: 10.1073/pnas.0914114107

89. Lin M, Pedrosa E, Shah A, et al. (2011) RNA-Seq of human neurons derived from iPS cells reveals candidate long non-coding RNAs involved in neurogenesis and neuropsychiatric disorders. PLoS One 6:e23356. doi: 10.1371/journal.pone.0023356

90. Kemp CR, Willems E, Wawrzak D, et al. (2007) Expression of Frizzled5, Frizzled7, and Frizzled10 during early mouse development and interactions with canonical Wnt signaling. Dev Dyn 236:2011-9. doi: 10.1002/dvdy.21198 
91. Cantilena S, Pastorino F, Pezzolo A, et al. (2011) Frizzled receptor 6 marks rare, highly tumourigenic stem-like cells in mouse and human neuroblastomas. Oncotarget 2:976-983.

92. De Calisto J, Araya C, Marchant L, et al. (2005) Essential role of non-canonical Wnt signalling in neural crest migration. Development 132:2587-97. doi: 10.1242/dev.01857

93. Snow GE, Kasper AC, Busch AM, et al. (2009) Wnt pathway reprogramming during human embryonal carcinoma differentiation and potential for therapeutic targeting. BMC Cancer 9:383. doi: 10.1186/1471-2407-9-383

94. Katoh M, Katoh M (2007) Comparative integromics on FZD7 orthologs: Conserved binding sites for PU.1, SP1, CCAAT-box and TCF/LEF/SOX transcription factors within 5'-promoter region of mammalian FZD7 orthologs. Int J Mol Med 19:529-533.

95. Zhao C, Avilés C, Abel R a, et al. (2005) Hippocampal and visuospatial learning defects in mice with a deletion of frizzled 9, a gene in the Williams syndrome deletion interval. Development 132:2917-27. doi: 10.1242/dev.01871

96. Kibar Z, Torban E, McDearmid JR, et al. (2007) Mutations in VANGL1 Associated with Neural-Tube Defects. N Engl J Med 356:1432-1437. doi: 10.1056/NEJMoa060651

97. Kibar Z, Vogan KJ, Groulx N, et al. (2001) Ltap, a mammalian homolog of Drosophila Strabismus/Van Gogh, is altered in the mouse neural tube mutant Loop-tail. Nat Genet 28:251-5. doi: 10.1038/90081

98. Paganoni S, Ferreira A (2005) Neurite extension in central neurons: a novel role for the receptor tyrosine kinases Ror1 and Ror2. J Cell Sci 118:433-46. doi: $10.1242 /$ jcs. 01622

99. Paganoni S, Bernstein J, Ferreira a (2010) Ror1-Ror2 complexes modulate synapse formation in hippocampal neurons. Neuroscience 165:1261-74. doi: 10.1016/j.neuroscience.2009.11.056

100. Endo M, Doi R, Nishita M, Minami Y (2011) Ror family receptor tyrosine kinases regulate the maintenance of neural progenitor cells in the developing neocortex. J Cell Sci 125:2017-2029. doi: 10.1242/jcs.097782

101. Lu X, Borchers AGM, Jolicoeur C, et al. (2004) PTK7/CCK-4 is a novel regulator of planar cell polarity in vertebrates. Nature 430:93-8. doi: $10.1038 /$ nature02677

102. Pinson KI, Brennan J, Monkley S, et al. (2000) An LDL-receptor-related protein mediates Wnt signalling in mice. Nature 407:535-8. doi: $10.1038 / 35035124$ 
103. Gomez AM, Burden SJ (2011) The extracellular region of Lrp4 is sufficient to mediate neuromuscular synapse formation. Dev Dyn 240:2626-33. doi: $10.1002 /$ dvdy. 22772

104. Zhou C-J, Zhao C, Pleasure SJ (2004) Wnt signaling mutants have decreased dentate granule cell production and radial glial scaffolding abnormalities. J Neurosci 24:121-6. doi: 10.1523/JNEUROSCI.4071-03.2004

105. Castelo-Branco G, Andersson ER, Minina E, et al. (2010) Delayed dopaminergic neuron differentiation in Lrp6 mutant mice. Dev Dyn 239:211-21. doi: 10.1002/dvdy.22094

106. Zechner D, Fujita Y, Hülsken J, et al. (2003) $\beta$-Catenin signals regulate cell growth and the balance between progenitor cell expansion and differentiation in the nervous system. Dev Biol 258:406-418. doi: 10.1016/S0012-1606(03)00123-4

107. Chenn A, Walsh C a (2002) Regulation of cerebral cortical size by control of cell cycle exit in neural precursors. Science (80- ) 297:365-9. doi: 10.1126/science.1074192

108. Pöschl J, Grammel D, Dorostkar M, et al. (2013) Constitutive activation of $\beta$ catenin in neural progenitors results in disrupted proliferation and migration of neurons within the central nervous system. Dev Biol 374:31932.

109. Machon O, Backman M, Machonova O, et al. (2007) A dynamic gradient of Wnt signaling controls initiation of neurogenesis in the mammalian cortex and cellular specification in the hippocampus. Dev Biol 311:223-37. doi: 10.1016/j.ydbio.2007.08.038

110. Chen B-Y, Wang X, Wang Z-Y, et al. (2013) Brain-derived neurotrophic factor stimulates proliferation and differentiation of neural stem cells, possibly by triggering the Wnt/ß-catenin signaling pathway. J Neurosci Res 91:30-41.

111. Hirabayashi $Y$, Itoh $Y$, Tabata $H$, et al. (2004) The Wnt/beta-catenin pathway directs neuronal differentiation of cortical neural precursor cells. Development 131:2791-801. doi: 10.1242/dev.01165

112. Fang WQ, Chen WW, Fu AY, Ip N (2013) Axin directs the amplification and differentiation of intermediate progenitors in the developing cerebral cortex. Neuron 79:665-679. doi: 10.1016/j.neuron.2013.06.017

113. Pei Y, Brun SN, Markant SL, et al. (2012) WNT signaling increases proliferation and impairs differentiation of stem cells in the developing cerebellum. Development 139:1724-1733. doi: 10.1242/dev.050104

114. Israsena $\mathrm{N}, \mathrm{Hu} \mathrm{M}, \mathrm{Fu} \mathrm{W}$, et al. (2004) The presence of FGF2 signaling determines whether beta-catenin exerts effects on proliferation or neuronal 
differentiation of neural stem cells. Dev Biol 268:220-31. doi: 10.1016/j.ydbio.2003.12.024

115. Dhara SK, Stice SL (2008) Neural Differentiation of Human Embryonic Stem Cells. J Cell Biochem 105:633-640.

116. Vallier L, Alexander M, Pedersen R a (2005) Activin/Nodal and FGF pathways cooperate to maintain pluripotency of human embryonic stem cells. J Cell Sci 118:4495-4509. doi: 10.1242/jcs.02553

117. Wang Q, Yang L, Alexander C, Temple S (2012) The niche factor syndecan-1 regulates the maintenance and proliferation of neural progenitor cells during mammalian cortical development. PLoS One. doi: 10.1371/journal.pone.0042883

118. Zhang J, Woodhead GJ, Swaminathan SK, et al. (2010) Cortical neural precursors inhibit their own differentiation via $\mathrm{N}$-cadherin maintenance of beta-catenin signaling. Dev Cell 18:472-479. doi: 10.1016/j.devcel.2009.12.025

119. Porlan E, Martí-Prado B, Morante-Redolat JM, et al. (2014) MT5-MMP regulates adult neural stem cell functional quiescence through the cleavage of N-cadherin. Nat Cell Biol 16:629-38. doi: 10.1038/ncb2993

120. Reimold AM, Grusby MJ, Kosaras B, et al. (1996) Chondrodysplasia and neurological abnormalities in ATF-2-deficient mice. Nature 379:262-265.

121. Mantamadiotis T, Lemberger T, Bleckmann SC, et al. (2002) Disruption of CREB function in brain leads to neurodegeneration. Nat Genet 31:47-54. doi: $10.1038 /$ ng882

122. Ackermann J, Ashton G, Lyons S, et al. (2011) Loss of ATF2 function leads to cranial motoneuron degeneration during embryonic mouse development. PLoS One 6:e19090. doi: 10.1371/journal.pone.0019090

123. Zhao C, Deng W, Gage FH (2008) Mechanisms and functional implications of adult neurogenesis. Cell 132:645-60. doi: 10.1016/j.cell.2008.01.033

124. Miranda CJ, Braun L, Jiang Y, et al. (2013) Aging Brain Microenvironment Decreases Hippocampal Neurogenesis Through Wnt-Mediated Survivin Signaling. Aging Cell 11:542-552. doi: 10.1111/j.14749726.2012.00816.x.Aging

125. Qu Q, Sun G, Murai K, et al. (2013) Wnt7a regulates multiple steps of neurogenesis. Mol Cell Biol 33:2551-2559. doi: 10.1128/MCB.00325-13

126. Encinas JM, Sierra A, Valcárcel-Martín R, Martín-Suárez S (2013) A developmental perspective on adult hippocampal neurogenesis. Int J Dev Neurosci 1-6. doi: 10.1016/j.ijdevneu.2013.04.001 
127. Moreno-Estellés M, González-Gómez P, Hortigüela R, et al. (2012) Symmetric expansion of neural stem cells from the adult olfactory bulb is driven by astrocytes via WNT7A. Stem Cells 30:2796-2809. doi: 10.1002/stem.1243

128. Slater PG, Ramirez VT, Gonzalez-Billault C, et al. (2013) Frizzled-5 receptor is involved in neuronal polarity and morphogenesis of hippocampal neurons. PLoS One 8:e78892. doi: 10.1371/journal.pone.0078892

129. Seib D, Corsini N, Ellwanger K, et al. (2013) Loss of dickkopf-1 restores neurogenesis in old age and counteracts cognitive decline. Cell Stem Cell 12:204-14.

130. Jang M-H, Bonaguidi M a, Kitabatake Y, et al. (2013) Secreted frizzled-related protein 3 regulates activity-dependent adult hippocampal neurogenesis. Cell Stem Cell 12:215-23. doi: 10.1016/j.stem.2012.11.021

131. Wexler EM, Paucer A, Kornblum HI, et al. (2009) Endogenous Wnt signaling maintains neural progenitor cell potency. Stem Cells 27:1130-41. doi: 10.1002/stem.36

132. Wexler EM, Geschwind DH, Palmer TD (2008) Lithium regulates adult hippocampal progenitor development through canonical Wnt pathway activation. Mol Psychiatry 13:285-92. doi: 10.1038/sj.mp.4002093

133. Fiorentini A, Rosi MC, Grossi C, et al. (2010) Lithium improves hippocampal neurogenesis, neuropathology and cognitive functions in APP mutant mice. PLoS One 5:e14382. doi: 10.1371/journal.pone.0014382

134. Imura T, Wang $X$, Noda $T$, et al. (2010) Adenomatous polyposis coli is essential for both neuronal differentiation and maintenance of adult neural stem cells in subventricular zone and hippocampus. Stem Cells 28:20532064. doi: $10.1002 /$ stem.524

135. Morgan-Smith M, Wu Y, Zhu X, et al. (2014) GSK-3 signaling in developing cortical neurons is essential for radial migration and dendritic orientation. Elife 2014:1-24. doi: 10.7554/eLife.02663.001

136. Orme M., Giannini a. ., Vivanco M., Kypta R. (2003) Glycogen synthase kinase3 and Axin function in a $\beta$-catenin-independent pathway that regulates neurite outgrowth in neuroblastoma cells. Mol Cell Neurosci 24:673-686. doi: 10.1016/S1044-7431(03)00229-X

137. Castaño Z, Gordon-Weeks PR, Kypta RM (2010) The neuron-specific isoform of glycogen synthase kinase-3beta is required for axon growth. J Neurochem 113:117-130. doi: 10.1111/j.1471-4159.2010.06581.x

138. Nelson S, Näthke IS (2013) Interactions and functions of the adenomatous polyposis coli (APC) protein at a glance. J Cell Sci 126:873-7. doi: 10.1242/jcs.100479 
139. Preitner N, Quan J, Nowakowski DW, et al. (2014) APC is an RNA-binding protein, and its interactome provides a link to neural development and microtubule assembly. Cell 158:368-382. doi: 10.1016/j.cell.2014.05.042

140. Bowman AN, van Amerongen R, Palmer TD, Nusse R (2013) Lineage tracing with Axin2 reveals distinct developmental and adult populations of $\mathrm{Wnt} / \beta$ catenin-responsive neural stem cells. Proc Natl Acad Sci 110:7324-9. doi: $10.1073 /$ pnas. 1305411110

141. Adachi K, Mirzadeh Z, Sakaguchi M, et al. (2007) Beta-catenin signaling promotes proliferation of progenitor cells in the adult mouse subventricular zone. Stem Cells 25:2827-2836. doi: 10.1634/stemcells.2007-0177

142. Ortega F, Gascón S, Masserdotti G, et al. (2013) Oligodendrogliogenic and neurogenic adult subependymal zone neural stem cells constitute distinct lineages and exhibit differential responsiveness to Wnt signalling. Nat Cell Biol 15:602-13. doi: 10.1038/ncb2736

143. Azim K, Fisher B, Hurtado-chong A, et al. (2014) Persistent Wnt/betaCatenin Signaling Determines Dorsalization of the Postnatal Subventricular Zone and Neural Stem Cell Specification into Oligodendrocytes and Glutamatergic Neurons. Stem Cells 32:1301-1312.

144. Ye F, Chen Y, Hoang T, et al. (2009) HDAC1 and HDAC2 regulate oligodendrocyte differentiation by disrupting the beta-catenin-TCF interaction. Nat Neurosci 12:829-38. doi: 10.1038/nn.2333

145. Reinecke K, Herdegen T, Eminel S, et al. (2013) Knockout of c-Jun N-terminal kinases 1, 2 or 3 isoforms induces behavioural changes. Behav Brain Res 245:88-95. doi: 10.1016/j.bbr.2013.02.013

146. Bevilaqua LRM, Kerr DS, Medina JH, et al. (2003) Inhibition of hippocampal Jun N-terminal kinase enhances short-term memory but blocks long-term memory formation and retrieval of an inhibitory avoidance task. Eur J Neurosci 17:897-902. doi: 10.1046/j.1460-9568.2003.02524.x

147. Pittenger C, Huang YY, Paletzki RF, et al. (2002) Reversible inhibition of CREB/ATF transcription factors in region CA1 of the dorsal hippocampus disrupts hippocampus-dependent spatial memory. Neuron 34:447-62.

148. Nakagawa S, Kim J-E, Lee R, et al. (2002) Regulation of neurogenesis in adult mouse hippocampus by cAMP and the cAMP response element-binding protein. J Neurosci 22:3673-82. doi: 20026301

149. Raivich G, Bohatschek M, Da Costa C, et al. (2004) The AP-1 transcription factor c-Jun is required for efficient axonal regeneration. Neuron 43:57-67. doi: 10.1016/j.neuron.2004.06.005 
150. Wichterle H, Przedborski S (2010) What can pluripotent stem cells teach us about neurodegenerative diseases? Nat Neurosci 13:800-804. doi: $10.1038 / \mathrm{nn} .2577$

151. Erceg S, Ronaghi M, Stojković M (2009) Human embryonic stem cell differentiation toward regional specific neural precursors. Stem Cells 27:7887. doi: 10.1634/stemcells.2008-0543

152. Zhang SC, Wernig M, Duncan ID, et al. (2001) In vitro differentiation of transplantable neural precursors from human embryonic stem cells. Nat Biotechnol 19:1129-1133. doi: 10.1038/nbt1201-1129

153. Broccoli V, Giannelli SG, Mazzara PG (2014) Modeling physiological and pathological human neurogenesis in the dish. Front Neurosci 8:183. doi: 10.3389/fnins.2014.00183

154. Kriks S, Shim J-W, Piao J, et al. (2011) Dopamine neurons derived from human ES cells efficiently engraft in animal models of Parkinson's disease. Nature 480:547-551. doi: 10.1038/nature10648

155. Sundberg M, Bogetofte H, Lawson T, et al. (2013) Improved Cell Therapy Protocols for Parkinson 's Disease Based on Differentiation Efficiency and Safety of hESC- , hiPSC- , and Non-Human Primate iPSC-Derived Dopaminergic Neurons. Stem Cells 31:1548-1562.

156. Du Z, Chen H, Liu H, et al. (2015) Generation and expansion of highly pure motor neuron progenitors from human pluripotent stem cells. Nat Commun 6:1-9. doi: 10.1038/ncomms7626

157. Reubinoff BE, Itsykson P, Turetsky T, et al. (2001) Neural progenitors from human embryonic stem cells. Nat Biotechnol 19:1134-1140.

158. Menendez L, Yatskievych TA, Antin PB, Dalton S (2012) Wnt signaling and a Smad pathway blockade direct the differentiation of human pluripotent stem cells to multipotent neural crest cells. Proc Natl Acad Sci 109:92209220. doi: 10.1073/pnas.1207810109

159. Elkabetz Y, Panagiotakos G, Al Shamy G, et al. (2008) Human ES cell-derived neural rosettes reveal a functionally distinct early neural stem cell stage. Genes Dev 22:152-65. doi: 10.1101/gad.1616208

160. Uysal-Onganer P, Kypta RM (2012) Wnt11 in 2011 - the regulation and function of a non-canonical Wnt. Acta Physiol 204:52-64. doi: 10.1111/j.1748-1716.2011.02297.x

161. Vijayaragavan K, Szabo E, Bossé M, et al. (2009) Noncanonical Wnt signaling orchestrates early developmental events toward hematopoietic cell fate from human embryonic stem cells. Cell Stem Cell 4:248-62. doi: 10.1016/j.stem.2008.12.011 
162. Terami H, Hidaka K, Katsumata T, et al. (2004) Wnt11 facilitates embryonic stem cell differentiation to Nkx2.5-positive cardiomyocytes. Biochem Biophys Res Commun 325:968-75. doi: 10.1016/j.bbrc.2004.10.103

163. Bengoa-Vergniory N, Gorroño-Etxebarria I, González Salazar I, Kypta RM (2014) A switch from canonical to noncanonical Wnt signaling mediates early differentiation of human neural stem cells. Stem Cells 32:3196-3208. doi: $10.1002 /$ stem.1807

164. Nicoleau C, Varela C, Bonnefond C, et al. (2013) ES Cells Neural Differentiation Qualifies the Role of Wnt/ $\beta$-Catenin Signals in Human Telencephalic Specification and Regionalization. Stem Cells 31:1763-1774. doi: $10.1002 /$ stem.1462

165. Ding VMY, Ling L, Natarajan S, et al. (2010) FGF-2 modulates Wnt signaling in undifferentiated hESC and iPS cells through activated PI3-K/GSK3beta signaling. J Cell Physiol 225:417-428.

166. Muroyama Y, Kondoh H, Takada S (2004) Wnt proteins promote neuronal differentiation in neural stem cell culture. Biochem Biophys Res Commun 313:915-921.

167. Slawny NA, O'Shea KS (2011) Dynamic changes in Wnt signaling are required for neuronal differentiation of mouse embryonic stem cells. Mol Cell Neurosci 48:205-16. doi: 10.1016/j.mcn.2011.07.010

168. Ten Berge D, Kurek D, Blauwkamp T, et al. (2011) Embryonic stem cells require Wnt proteins to prevent differentiation to epiblast stem cells. Nat Cell Biol 13:1070-5. doi: 10.1038/ncb2314

169. Ying Q-L, Wray J, Nichols J, et al. (2008) The ground state of embryonic stem cell self-renewal. Nature 453:519-23. doi: 10.1038/nature06968

170. Atlasi Y, Noori R, Gaspar C, et al. (2013) Wnt signaling regulates the lineage differentiation potential of mouse embryonic stem cells through Tcf3 downregulation. PLoS Genet 9:e1003424. doi: 10.1371/journal.pgen.1003424

171. Osei-Sarfo K, Gudas LJ (2014) Retinoic acid suppresses the canonical Wnt signaling pathway in embryonic stem cells and activates the noncanonical Wnt signaling pathway. Stem Cells 32:2061-2071. doi: 10.1002/stem.1706

172. Wu C-I, Hoffman J a., Shy BR, et al. (2012) Function of Wnt/beta-catenin in counteracting Tcf3 repression through the Tcf3-beta-catenin interaction. Development 139:2118-2129. doi: 10.1242/dev.076067

173. Lee C-T, Bendriem RM, Kindberg AA, et al. (2015) Functional Consequences of 17q21.31/WNT3-WNT9B Amplification in hPSCs with Respect to Neural Differentiation. Cell Rep 10:616-632. doi: 10.1016/j.celrep.2014.12.050 
174. Li X-J, Zhang X, Johnson MA, et al. (2009) Coordination of sonic hedgehog and Wnt signaling determines ventral and dorsal telencephalic neuron types from human embryonic stem cells. Development 136:4055-4063. doi: 10.1242/dev.036624

175. Lange C, Mix E, Frahm J, et al. (2011) Small molecule GSK-3 inhibitors increase neurogenesis of human neural progenitor cells. Neurosci Lett 488:36-40.

176. Inestrosa NC, Montecinos-Oliva C, Fuenzalida M (2012) Wnt signaling: role in Alzheimer disease and schizophrenia. J Neuroimmune Pharmacol 7:788807. doi: 10.1007/s11481-012-9417-5

177. Fancy SPJ, Baranzini SE, Zhao C, et al. (2009) Dysregulation of the Wnt pathway inhibits timely myelination and remyelination in the mammalian CNS. Genes Dev 23:1571-1585. doi: 10.1101/gad.1806309

178. Encinas JM, Michurina T V, Peunova N, et al. (2011) Division-coupled astrocytic differentiation and age-related depletion of neural stem cells in the adult hippocampus. Cell Stem Cell 8:566-579.

179. Sancho RM, Law BMH, Harvey K (2009) Mutations in the LRRK2 Roc-COR tandem domain link Parkinson's disease to Wnt signalling pathways. Hum Mol Genet 18:3955-3968. doi: 10.1093/hmg/ddp337

180. Marchetti B, Pluchino S (2013) Wnt your brain be inflamed? Yes, it Wnt! Trends Mol Med 19:144-56. doi: 10.1016/j.molmed.2012.12.001

181. Piccin D, Tufford A, Morshead CM (2015) Neural stem and progenitor cells in the aged subependyma are activated by the young niche. Neurobiol Aging 35:1669-1679. doi: 10.1016/j.neurobiolaging.2014.01.026

182. Aloia L, Di Stefano B, Sessa A, et al. (2014) Zrf1 is required to establish and maintain neural progenitor identity. Genes Dev 28:182-197. doi: 10.1101/gad.228510.113 